\title{
The effectiveness of e-Learning on biosecurity practice to slow the spread of invasive alien species
}

\author{
Caitriona Shannon - Paul D. Stebbing • Claire H. Quinn • Daniel A. Warren • \\ Alison M. Dunn (1)
}

Received: 19 August 2019/Accepted: 28 April 2020/Published online: 18 May 2020

(C) The Author(s) 2020

\begin{abstract}
Online e-Learning is increasingly being used to provide environmental training. Prevention measures including biosecurity are essential to reducing the introduction and spread of invasive alien species (IAS) and are central to international and national IAS policy. This paper is the first to evaluate the effectiveness of e-Learning as a tool to increase awareness, risk perception and biosecurity behaviour in relation to IAS among individuals conducting work activities or research (fieldwork) in the field. We surveyed participants (a mixture of students and professionals) before, and 6 months after undertaking an e-Learning course on IAS and biosecurity practices.
\end{abstract}

Electronic supplementary material The online version of this article (https://doi.org/10.1007/s10530-020-02271-z) contains supplementary material, which is available to authorized users.

C. Shannon · D. A. Warren · A. M. Dunn ( $\varangle)$ School of Biology, Faculty of Biological Sciences, University of Leeds, Leeds LS6 9JT, UK

e-mail: A.Dunn@leeds.ac.uk

P. D. Stebbing

APEM Limited, International House, International

Business Park, Southampton SO18 2RZ, UK

C. H. Quinn

Sustainability Research Institute, School of Earth and Environment, University of Leeds, Leeds LS6 9JT, UK

A. M. Dunn

Water@leeds, University of Leeds, Leeds LS6 9JT, UK
Awareness of IAS and self-reported biosecurity behaviour increased after e-Learning among students and professionals. Students had a lower awareness of IAS than professionals before training $(20 \%$ of students vs $60 \%$ of professionals), but after training students showed a greater increase in awareness which led to similar levels of awareness post-training (81\%). Prior to training, risk perception was also lower amongst students than professionals (33\% of students and $59 \%$ of professionals were aware of the risk that their activities posed to the accidental spread of IAS). There was no change in risk perception amongst professionals after training, however training led to a doubling of risk perception in students. E-Learning also led to an increase in reported biosecurity behaviour and cleaning practices and there were higher levels of biosecurity cleaning amongst professionals. The higher awareness and better biosecurity amongst professionals is likely to reflect their familiarity with the issues of IAS and day-to-day activities in the field. Our results suggest that e-Learning is an effective tool to raise awareness and encourage behaviour change among field workers and researchers in an attempt to reduce the risk of accidental introduction and spread of IAS.

Keywords Behaviour change - Biosecurity - eLearning - Invasive alien species $\cdot$ Risk perception . Training 


\section{Introduction}

Invasive alien species and biosecurity

Invasive alien species (IAS) have negative ecological, economic or social impacts, or adversely affect human health in their novel range. Once established, control of IAS is difficult and expensive and total eradication is often infeasible (Hulme et al. 2017). Therefore methods to prevent the risk of introduction and spread are increasingly being recognised as the most cost effective means of reducing the impacts of IAS. Prevention is central to the Convention on Biological Diversity (CBD), EU Marine Strategy Framework Directive (MSFD), EU IAS Regulation (1143/2014) and the Invasive Non-Native Species Strategy for Great Britain (Perrings et al. 2005). Human activities such as transport, trade and tourism are all associated with pathways of introduction and secondary spread of IAS in the marine, freshwater and terrestrial environment (Hulme 2009; Saul et al. 2017).

Biosecurity measures are activities aimed at preventing the introduction and secondary spread of IAS. For example, good hygiene practices reduce the risk that activities in the field might lead to the spread of IAS. Practitioners and researchers working in the field could potentially spread IAS. Biosecurity measures include; ensuring that equipment taken into the field is free from IAS; fieldwork preparation planning (for example visiting an IAS infested site last during a day of site visits, accessing a site on foot to minimise the risk of contaminating vehicles); cleaning measures to remove/kill IAS potentially attached to clothing or equipment (Anderson et al. 2015; Sebire et al. 2018; Shannon et al. 2018a).

To address the issue of IAS and promote good biosecurity behaviour among stakeholders, communication campaigns have been created to raise awareness of the risk of IAS and to modify public attitudes and encourage positive risk-reducing changes in behaviour such as adopting biosecurity measures (pro-environmental behaviour). The Stop Aquatic Hitchhikers: Clean Drain Dry campaign in the USA (Aquatic Nuisance Species Task Force 2020) and New Zealand's Check Clean Dry campaign (Ministry for Primary Industries 2020) attempt to educate and raise awareness of the impact of accidentally spreading aquatic invasive species among recreational users and to improve biosecurity practice amongst water users.
In the UK, the Department for Environment, Food and Rural Affairs (Defra) launched the first invasive species specific biosecurity campaign Check Clean Dry in 2011 in response to the first reports of the invasive non-native Dikerogammarus villosus (Killer Shrimp) (Defra 2020). The campaign is now led by the Great Britain Non-Native Species Secretariat (GBNNSS) on behalf of Defra, the Welsh Government and the Scottish Government. The aim of the Check Clean Dry campaign in the UK (similar to those of the USA and New Zealand) was to raise awareness of the risk posed by stakeholders that use the aquatic environment for work or leisure (e.g. anglers, recreational boaters), and to encourage stakeholders to take practical measures to reduce their risk of accidental introduction and secondary spread of aquatic IAS on equipment (Box 1). More recently, a recent survey in the UK on awareness of IAS amongst anglers and boaters had increased over the last 10 years, although awareness remains low amongst public overall (67\% general public aware compared to $87 \%$ of anglers and $83 \%$ of boaters (Creative Research 2018)). Biosecurity initiatives have also been designed for the terrestrial environment, for example the Forestry Commission in England and Scotland promote the Keep it Clean campaign (Forestry Commission 2020) which encourages individuals to take measures to reduce the spread of pests and disease.

Since 2011, e-Learning courses have been designed to support the UK's Check Clean Dry campaign by raising awareness among stakeholders and targeting behaviours that pose a risk of accidentally spreading IAS in the marine, freshwater and terrestrial environment. The GBNNSS have an e-Learning platform on their website with six modules covering biosecurity and IAS, these are used by government and stakeholders such as anglers, boaters, environmental practitioners and site workers(GB Non-Native Species Secretariat 2020). Field researchers are an important group of stakeholders that undertake activities in the aquatic and terrestrial environment (e.g. surveying and sampling), which could potentially bring them into contact with IAS (knowingly or unknowingly) and facilitate their spread (Shannon et al. 2018b; Sutcliffe et al. 2018). Field researchers therefore represent an important group of individuals that would benefit from e-Learning training. The Better Biosecurity e-Learning course designed by the University of Leeds, Cefas, Environment Agency and the GBNNSS in 2015 
(University of Leeds 2020), targets individuals conducting work activities or research (fieldwork) in the marine, freshwater and terrestrial environment, including students and professionals. However, since this investment into e-Learning training, there has yet to be a measure of its effectiveness.

\section{Box 1. Check Clean Dry campaign}

Check your equipment, boat and clothing after leaving the water for mud, aquatic animals or plant material.

Remove anything you find and leave it at the site.

Clean everything thoroughly as soon as you can, paying particular attention to areas that are damp or hard to access. Use hot water if possible.

Dry everything for as long as you can before using elsewhere as some invasive plants and animals can survive for over two weeks in damp conditions.

Environmental training and e-Learning

Many early environmental behavioural studies assumed that knowledge is a necessary pre-condition for behavioural change through its influence on a person's attitude; the information deficit model (reviewed in Owens and Driffill 2008; Boyes and Stanisstreet 2012). However it has repeatedly been found that knowledge of an issue alone does not necessarily translate directly into behaviour change to address that problem (Hungerford and Volk 1990; Rothlisberger et al. 2010; McKenzie-Mohr and Schultz 2014). Instead, behavioural models use 'tools' to evaluate more effective strategies to encourage and foster behaviour change (e.g. education, persuasion, incentivisation, coercion, and training) (McKenzieMohr and Schultz 2014). Whilst education focuses on imparting knowledge and developing understanding, environmental training focuses on developing the necessary skills to address the issue (Michie et al. 2011). Training is described by Salas et al. (2006) as the acquisition of knowledge, skills and attitudes that lead to improved performance. Behaviour change is the real purpose behind any training effort; therefore for training to be considered effective, a behavioural change should ideally be observed post-training (Gilpin-Jackson and Bushe 2007). Therefore, environmental training is fundamental to any successful activity of environmental management or conservation (Jabbour 2013).

E-Learning, or electronic learning, is a form of distance learning undertaken by an individual on a computer or other electronic device (Arkorful and Abaidoo 2014; Azeiteiro et al. 2015). As with traditional training courses, e-Learning courses attempt to use real life examples for individuals to relate to situations and make connections with their activities (Bouhnik and Marcus 2006; Liaw et al. 2007; Liaw 2008). E-Learning can be extremely flexible as it uses network technologies to facilitate learning at any time or any place (Lim et al. 2007). Many individuals (including researchers) seek professional development but may not have time or money to attend face-to-face courses or to undertake laboratory fieldwork training (Bacelar-Nicolau et al. 2009).

Research suggests that e-Learning can provide an effective alternative to face-to-face training in higher education and achieve the same performance (Azeiteiro et al. 2015). According to Noesgaard and Ørngreen (2015), the most common way to measure effectiveness is quantitatively using pre-and posttests; and effectiveness can be defined in many ways (e.g. learning outcome, transfer, attitude, satisfaction). In a study looking at awareness, attitudes and behaviour, students had acquired knowledge and performance as well as motivation (willingness) to learn and act after completing a postgraduate e-Learning course in Environmental Science (Bacelar-Nicolau et al. 2009). Similarly, e-Learning has been utilised as an alternative to instructor-led training to meet the fire safety training needs of owners, operators, with awareness, attitudes and test score improving after training (Harrington and Walker 2009). The effectiveness of e-Learning is yet to be looked at in the context of IAS and biosecurity among field practitioners and researchers.

We present the first study of the effectiveness of e-Learning in influencing the awareness of IAS and in influencing biosecurity behaviours of people working in the environment. By surveying individuals before and after e-Learning, we aim to 
investigate the effectiveness of e-Learning training on awareness of IAS, risk perception of field activities accidentally spreading IAS, and on an individuals' self-reported cleaning and self-reported biosecurity practices.

\section{Methodology}

The Better Biosecurity e-Learning course was made freely available on two platforms. The first was available to staff and students at the University of Leeds on an internal Virtual Learning Environment (VLE), 'Minerva'. The second was available on 'Blackboard Open' software, and was aimed at individuals undertaking fieldwork or involved in industry, agriculture, trade, site surveys, education, or recreation. The Better Biosecurity e-Learning course took between one to two hours to complete and participants were able to save and return to the course at any time. The course guided the individual through four sections: introduction to IAS and the importance of biosecurity, fieldwork preparation and consideration of the risks of IAS spread, the Check Clean Dry campaign, and a set of multiple-choice questions. The course's learning objectives to achieve behaviour change were as followed:

1. To make participants aware of the impact of IAS, of routes of IAS spread and of the risk fieldwork poses in relation to introduction and spread.

2. For individuals to gain or advance awareness and knowledge of practical skills for better biosecurity practice.

3. To advance ability to critically evaluate different types of fieldwork scenarios to determine the best methods to reduce the spread of IAS.

The e-Learning course used a mixture of pictures, videos and interactive images in order to engage the individual. Formative multiple-choice questions presented during the course allowed users to check their understanding; in the case of an incorrect answer, the individual was shown the correct answer with feedback. At the end of the e-Learning course, there were 10 multiple-choice questions in which $100 \%$ was required in order to pass and receive a completion certificate. If participants failed to get $100 \%$ they were encouraged to redo the test until $100 \%$ was achieved.
Sampling

At the University of Leeds, staff and students (undergraduate and postgraduate) within relevant disciplines such as geography, environmental studies, biology, ecology and conservation were made aware of the e-Learning course through being sent monthly invitation emails. Students were also directed to the e-Learning course at induction sessions for undergraduate and postgraduate courses, and in relevant taught modules in the faculties of Environment and of Biological Sciences. The e-Learning was embedded into the Health and Safety risk assessment process for students and staff undertaking fieldwork within these faculties.

Information about the e-Learning course was disseminated externally to a wide range of organisations through email and social media promotions (Twitter and Facebook) during the same time period. Handouts to promote the e-Learning course were also provided at various IAS focused meetings and conferences (e.g. British Ecological Society Annual Meeting, the International Conference on Aquatic Invasive Species), as well as directly targeting organisations that undertake field research (water companies, consultancies, regulators, conservation authorities). The e-Learning course was also promoted on the GBNNSS website and the University of Leeds website. All participation on the e-Learning course was voluntary. Of those who took the e-Learning module $(\mathrm{n}=1906) 38 \%(\mathrm{n}=729)$ completed the quiz with $100 \%$.

\section{Survey design}

After enrolling on to the course, participants were asked to undertake the pre e-Learning online survey (supplementary information); this was optional and the participant was able to start the e-Learning without having to complete the survey.

All individuals were asked whether they would be willing to participate in a post e-Learning survey. All individuals that agreed to be contacted for a follow up survey were emailed 6 months after completing the pre e-Learning survey and Better Biosecurity $e$ Learning course. This time interval was used to allow participants the opportunity to apply their new 
behaviour at work/study before we measured any behaviour change. Both e-Learning platforms (VLE and Blackboard Open) were cross-checked against participants that agreed to be followed up to check that the e-Learning had been fully completed before participants were emailed the link to the post e-Learning survey.

For comparison of awareness of IAS and/or biosecurity campaigns, risk perception of field activities, self-reported cleaning and self-reported biosecurity practice, identical questions were asked in the pre and post e-Learning online survey (supplementary information).

The surveys were created using Online Surveys software (https://www.onlinesurveys.ac.uk/). The online surveys satisfied the University of Leeds' guidelines on ethical conduct (Ethics reference BIOSCI 15-023). A pilot study (internal $n=5$, external $n=5$ ) was conducted to ensure the pre and post surveys worked effectively and to reduce ambiguity or misinterpretation of the questions. This pilot data was not used in the overall analysis.

The pre e-Learning surveys were conducted between November 2015 and July 2018 and were designed to take no longer than $10 \mathrm{~min}$. Post e-Learning surveys were conducted 6 months after the individual had completed the initial survey and training.

Surveys included a one page introductory information sheet about the project aims and objectives and stated that participants would not be identifiable in the research outputs. Due to a variety of different definitions used for IAS in the literature (including INNS and non-indigenous species), a definition of IAS was given at the start of the online survey. Participants were asked for consent before being able to continue with the survey.

\section{Demographic data}

The first section of the survey collected demographic data on the participants (gender and age). Participants who took the training on Blackboard Open were asked to identify what organisation they worked for, participants who took the training on the VLE were known to be working or studying at the University of Leeds. All participants were asked if they were studying; if yes, participants were asked for their department and what level of education (undergraduate, postgraduate, $\mathrm{PhD})$.
Self-reported biosecurity cleaning practices

The second section of the survey focused on selfreported biosecurity cleaning practices undertaken by respondents. There are many difficulties with measuring actual behaviour using surveys, therefore researchers rely on reported behaviour in an attempt to get closer to reality (Corral-Verdugo 1997). To increase the value of participants' answers and to increase accuracy, questions concerning the cleaning of equipment, transport and clothing were asked before participants answered questions on IAS and biosecurity behaviour. This was to avoid participants changing answers in relation to the research question on what they would think might be a more socially desirable answer.

All participants were asked if they used equipment in the field (yes or no). To determine self-reported cleaning practices, participants that answered yes to using equipment in the field were then asked questions about cleaning practices for equipment. Participants were asked a series of questions (based on the Check Clean Dry campaign) about how often they cleaned equipment before arriving and before leaving a site, as well as whether they dried equipment between uses and if they used the same equipment at multiple sites a day (measured using a Likert scale from always to never). Participants were given a selection of cleaning methods to choose from and were able to choose as many methods of cleaning equipment that they undertook. These included measures such as rinsing in cold water, cleaning with disinfectant and drying either before arriving at a site, before leaving a site or upon returning after fieldwork.

All participants were asked how they arrived at field sites. Participants that arrived by car/bicycle/other wheeled vehicles and by boat were then asked questions about how often they cleaned tyres/wheels/ boat hulls before arriving and before leaving a site as well as whether they dried transport between uses (again using a Likert scale from always to never). Participants were again allowed to choose the method that they took to clean transport before arriving at a site, before leaving a site or upon returning after fieldwork. Participants that did not arrive by car/ bicycle/other wheeled vehicle or by boat in the field were automatically forwarded to answer questions about cleaning practices for outerwear/footwear. 
All participants were asked how often they cleaned footwear and outerwear in-between site visits (Likert scale from always to never), and what cleaning methods they used. These included measures such as rinsing in cold water, cleaning with disinfectant and drying either before arriving at a site, before leaving a site or upon returning after fieldwork.

All cleaning questions for equipment, transport and footwear/outerwear were used to generate a 'selfreported cleaning score' for the analysis. The response given to how often participants cleaned before arriving, before departing, after returning and dried in between was scored from 0 to 4 (e.g. never $=0$, rarely $=1$, sometimes $=2$, often $=3$, always $=4$ ). For each variable (equipment, transport and footwear/outerwear) each respondent was given a mean score and then an overall combined score. Participants that did not complete all variables were given a mean score based on one, or both of the other variables. The higher the score, the better the self-reported biosecurity cleaning practices of the individual.

\section{Awareness of IAS and biosecurity campaigns}

To measure awareness, participants were asked if they were aware of IAS and/or any campaigns in relation to biosecurity (yes/no). If participants answered yes, they were then asked to give further explanation and details.

\section{Risk perception of activities accidentally spreading IAS}

Risk perceptions are fundamental components that are influenced by, and frame attitudes and beliefs, and can help predict intentions and behaviours (O'Connor et al. 1999; Estévez et al. 2015). To determine risk perception, participants were asked whether they considered their field activities to pose a risk in terms of spreading IAS (yes or no). Those that answered yes were asked to rank their risk from low (1) to high (5).

\section{Self-reported biosecurity practice}

The final section of the survey asked all respondents to self-report on whether they consciously employed biosecurity measures in the field (yes or no). Asking individuals to self-report on their behaviour allowed us to investigate whether e-Learning had an effect on self-reported biosecurity practice as self-reporting has been recognised as an important factor in achieving behaviour change (Corral-Verdugo 1997).

\section{Data analysis}

A total of 666 individuals completed the pre e-Learning survey. However, fewer individuals provided information that enabled us to carry out an analysis $(n=62)$ on data for the same individual before and after training. We therefore conducted analysis of the whole dataset and also undertook a further analysis on the subset of paired data.

All statistical analyses were carried out in $\mathrm{R}$ version 3.5.0 (R Core Team 2016). We investigated the effect of training and position (student or professional) on an individual's awareness, risk perception, self-reported biosecurity cleaning practices and self-reported biosecurity practice. Data pertaining to awareness and risk perception, relative to respondent position (i.e. student/professional) and training status (i.e. before and after) were analysed using Generalised Linear Models (GLMs), fitted with a binomial error structure. GLMs were simplified to minimum adequate models (Crawley 2007). Variables were discarded from the model when they did not significantly increase deviance. Self-cleaning practices reported by respondents using a Likert scale, were used in conjunction with other replies to generate a composite cleaning score. The data were analysed using a linear model (ANOVA) (commonly used for analysis of Likert data (Goodwin et al. 2018)) allowing us to explore potential interaction terms. However, as Likert scale data are in fact ordinal data, we also undertook Mann-Whitney tests.

We also analysed the data for the subset of respondents who provided us with information to compare paired data. Again, we investigated the effect of training and position on an individual's awareness, risk perception, self-reported biosecurity cleaning and self-reported biosecurity practice.

\section{Results}

Pre and post survey return rate and demographics

A total of 666 individuals completed the pre e-Learning survey; of these individuals 461 (69\%) were students and $205(31 \%)$ were professionals. Students 
included individuals undertaking undergraduate (56\%), taught postgraduate $(27 \%)$ and $\mathrm{PhD}(27 \%)$ studies. Professionals included practitioners and volunteers working in the field of conservation and environmental management, academic lecturers and field staff.

A total of 14 different universities and research institutes were represented by the students; 10 in the UK, 1 in Ireland, 1 in Germany and 2 in the USA. Among the professionals, 124 different organisations and companies were represented, as were participants that were self-employed and retired. Organisations were based worldwide and included UK, USA, Australia, Mexico, Holland, Kenya, Norway, New Zealand, and India.

A range of age groups were represented in the pre e-Learning survey, with the majority of participants aged between 18 and $25(63 \%)$ then 26 and $35(16 \%)$ followed by 26 and $45(9 \%), 46$ and $55(6 \%)$ and finally 66 or over $(1 \%)$ ( $0.3 \%$ preferred not to say).

All participants were asked to select up to four disciplinary areas that best described their area of work, research or education (Fig. 1). The most common discipline selected was Biology (37\%), followed by Ecology (35\%), Conservation (29\%) and Environmental Science (18\%). The totals sum up to $>100 \%$ as participants could select more than one discipline.

A total of 274 participants agreed to participate in the follow up survey. Of these, 78 participants completed the post e-Learning survey of which 32 (41\%) were students and 46 (59\%) were professionals. A total of 62 individuals completed the pre e-Learning survey and post survey and provided sufficient information to conduct an analysis of the paired data. Of these individuals, $23(37 \%)$ were students and 39 $(63 \%)$ were professionals $23(37 \%)$ were students and $39(63 \%)$ were professionals.

The effect of training on awareness of IAS and/ or biosecurity campaigns

Participants were asked before and after the e-Learning course whether they were aware of IAS and/or campaigns in relation to biosecurity. Awareness of IAS and/or biosecurity campaigns increased after undertaking the e-Learning course (Fig. 2a, Table 1). Before e-Learning, $32 \%$ of participants were aware of IAS and/or biosecurity, this increased to $81 \%$ of participants after e-Learning.
Awareness was significantly affected by the interactions between position and training (Table 1). Initial awareness was higher in professionals (60\%) than students (20\%). However, students had a greater increase in awareness after e-Learning compared to professionals, leading to a similar awareness posttraining; student awareness increased to $80 \%$ and professional's awareness increased to $81 \%$ (Fig. 2a).

Participants that were aware of campaigns (or guidance) gave examples of Check Clean Dry, Be Plant Wise, ballast water management, EU IAS Regulation (1143/2014) and Forestry Commission guidance.

Those individuals who took the survey both pre and post e-Learning showed a higher level of initial awareness. $82 \%$ of professionals that returned for the follow up survey were aware of IAS and/or campaigns before training, whereas, amongst those who did not complete the follow up survey, only $66 \%$ were aware of IAS. Likewise, $65 \%$ of students that returned for the follow up survey were aware of IAS and/or campaigns before training compared to $16 \%$ of students that were aware before training who did not complete the follow up survey. This highlights self-selection bias in the analysis, where these participants had higher awareness of IAS and/or campaigns before training compared to those that did not return.

However, the results of the analysis of the paired and the overall data set were in accord; awareness was significantly increased after training, with students exhibiting a greater improvement overall when compared to professionals (Table 2).

The effect of training on risk perception

Participants were asked whether they considered their activities to pose a risk of accidentally spreading IAS. Before undertaking the e-Learning course, $41 \%$ of participants considered their activities to pose a risk of accidentally spreading IAS, this increased to $56 \%$ after e-Learning. Before e-Learning, those that did consider their activities a risk considered it a medium to low risk on the Likert scale. After e-Learning participants that considered their activities to pose a risk considered it a medium to high risk on the Likert scale.

Risk perception was also significantly affected by the interaction between position and training (Table 1). Initial risk perception was higher among professionals (59\%) compared to students (33\%). 
Fig. 1 Number of participants within each disciplinary area noting that participants could choose up to 4 areas

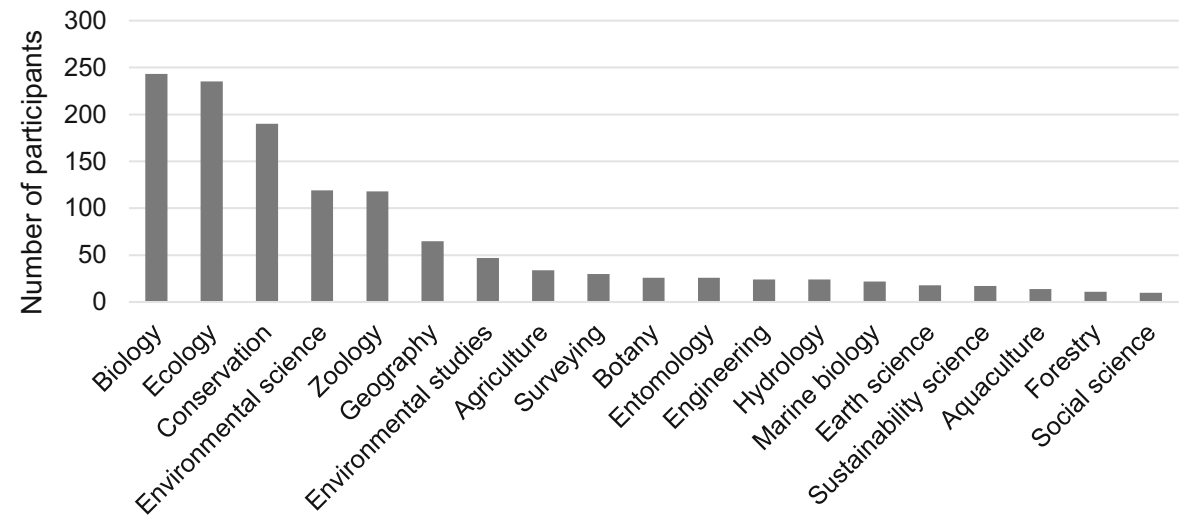

Disciplinary area
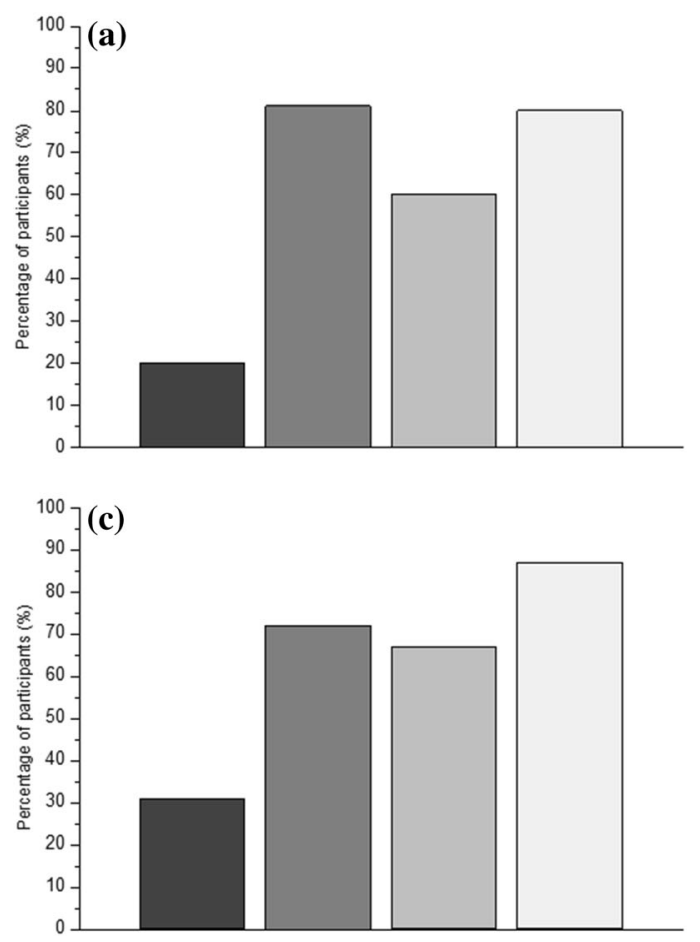
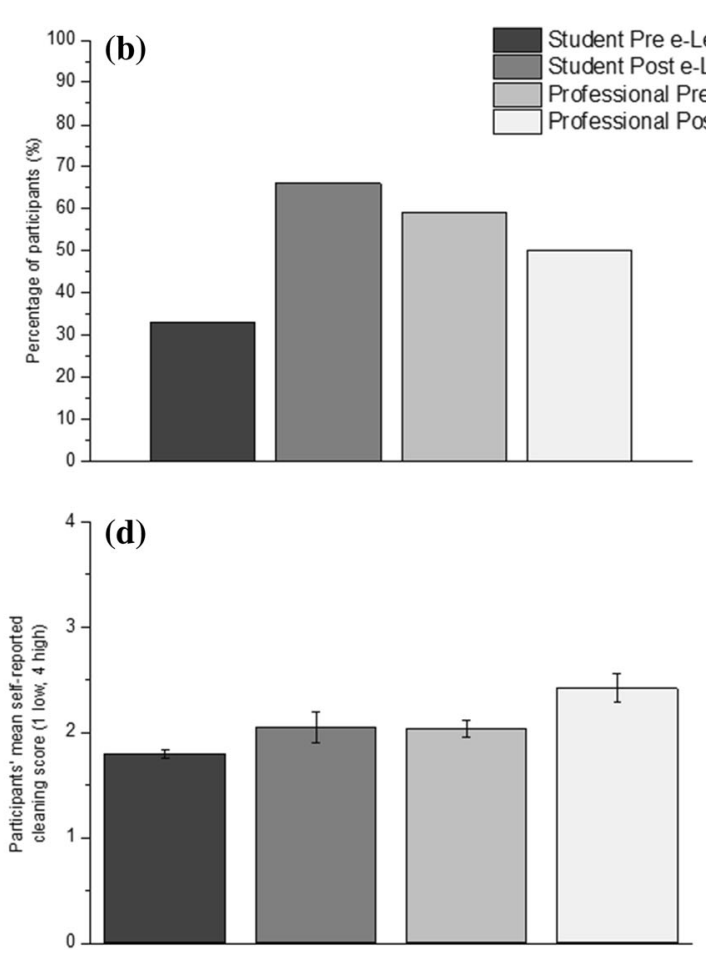

Fig. 2 Respondents' awareness of IAS and/or biosecurity campaigns (a), risk perception (that activities pose a risk of IAS spread) (b), self-reported biosecurity practice (c) and self-reported cleaning behaviour (d) before and after undertaking the e-Learning

Whilst student's risk perception doubled after e-Learning $(66 \%)$, risk perception of professionals' did not change significantly (Fig. 2b).

Exploration of the paired data for those individuals who completed both pre and post training surveys showed a similar pattern, although there was no significant effect on risk perception of position, training or by the interaction (Table 2).
The effect of training on self-reported biosecurity practice

Participants were asked before and after e-Learning whether they consciously employed biosecurity measures in the field. Self-reported biosecurity practice increased after undertaking the e-Learning course (Table 1; Fig. 2c). Before e-Learning, $42 \%$ of participants reported consciously employing biosecurity 
Table 1 The influence of e-Learning (training) and position (student or professional) on awareness of IAS, risk perception (perception that their activities pose a risk of spreading IAS), self-reported biosecurity practices, and self-reported cleaning behaviour

\begin{tabular}{|c|c|c|c|c|}
\hline & Estimate & SE & $\mathrm{z}$ value & $P$ \\
\hline \multicolumn{5}{|l|}{ Awareness } \\
\hline Training & 4.7228 & 1.0166 & 4.646 & $<0.001$ \\
\hline Position & 3.6823 & 0.6923 & 5.319 & $<0.001$ \\
\hline Training: position & -1.8675 & 0.6142 & -3.040 & 0.00236 \\
\hline \multicolumn{5}{|l|}{ Risk perception } \\
\hline Training & 3.0964 & 0.8371 & 3.699 & $<0.001$ \\
\hline Position & 2.7946 & 0.5877 & 4.755 & 0.000216 \\
\hline Training: position & -1.7206 & 0.5054 & -3.404 & 0.000663 \\
\hline \multicolumn{5}{|c|}{ Self-reported biosecurity practice } \\
\hline Training & 2.3207 & 0.9343 & 2.484 & 0.01299 \\
\hline Position & 2.1050 & 0.6897 & 3.052 & 0.00227 \\
\hline Training: position & -0.5731 & 0.6153 & -0.931 & 0.35167 \\
\hline \multicolumn{5}{|c|}{ Self-reported cleaning behaviour } \\
\hline Training & 1.7971 & 0.11060 & 2.772 & 0.00571 \\
\hline Position & 0.3066 & 0.07730 & 3.336 & 0.00089 \\
\hline Training: position & 0.1296 & 0.2223 & 0.583 & 0.5602 \\
\hline
\end{tabular}

Colon (:) represents the interaction of training and position. Estimates of the regression coefficient indicate the mean change/ difference in the response variables (i.e. perception, self-reported biosecurity, and self-reported cleaning) as predictor variables change (i.e. pre vs post-training and student vs professional)

Table 2 The influence of e-Learning (training) and position (student or professional) on awareness of IAS, risk perception (perception that their activities pose a risk of spreading IAS), selfreported biosecurity practice and self-reported cleaning behaviour (colon '?' represents the interaction of training and position) for the subtest of participants who undertook both pre and post surveys

\begin{tabular}{lrrrr}
\hline & Estimate & SE & z value & $P$ \\
\hline Awareness & & & & \\
Training & 2.3390 & 0.7523 & 3.109 & 0.00188 \\
Position & 1.9617 & 0.5973 & 3.284 & 0.00102 \\
Training: position & -2.5042 & 0.9473 & -2.644 & 0.00821 \\
Risk perception & & & & \\
Training & 0.321 & 0.4178 & -0.819 & 0.413 \\
Position & 0.4890 & 0.4995 & 0.979 & 0.328 \\
Training: position & -1.7458 & 0.9308 & -1.876 & 0.061 \\
Self-reported biosecurity practice & & & \\
Training & 22.955 & 3.988 & 5.755 & $<0.001$ \\
Position & 22.281 & 3.705 & 6.283 & $<0.001$ \\
Training: position & -11.345 & 4.736 & -2.395 & 0.0166 \\
Self-reported cleaning behaviour & 0.1624 & 0.1632 & 0.995 & 0.32153 \\
Training & 0.5791 & 0.1847 & 3.135 & 0.00215 \\
Position & -0.2104 & 0.7176 & -0.293 & 0.770 \\
Training: position & & & & \\
\hline
\end{tabular}

but was not significantly affected by the interactions between position and training (Table 1). measures in the field, this increased to $81 \%$ after e-Learning. Self-reported behaviour was higher amongst professionals than amongst students (Fig. 2c) 
Similarly, for the paired data analysis, self-reported biosecurity significantly improved following training, with professionals reporting better biosecurity practices when compared to students. Amongst professionals that returned for the follow up survey, selfreported biosecurity practices increased from $79 \%$ (pre training), to $87 \%$ (post training). Likewise, amongst re-surveyed students, self-reported biosecurity practices increased from $26 \%$ (pre training) to $78 \%$ (post training) (Table 2).

The effect of training on self-reported cleaning behaviour

Answers to questions on how they cleaned equipment, transport and footwear/outerwear were used to calculate a cleaning score for each participant before and after e-Learning. The overall mean cleaning score significantly increased after training. Self-reported cleaning behaviour was higher for professionals than students, and there was no significant effect of the interaction between position and training (Fig. 2d, Table 1). The result of the non-parametric analysis were in accord with those of the parametric analysis.

In contrast, training had no significant effect on cleaning behaviour in the paired data cohort. However, there was a significant difference between professionals and students, with self-reported cleaning behaviour higher among professionals (Table 2).

\section{Discussion}

E-Learning is increasingly being used as a method of environmental training to raise awareness and change behaviours among individuals. E-Learning is a useful tool in the Environmental Sciences and other disciplines; individuals seek professional development online as they do not always have time to attend face-to-face training courses (Bacelar-Nicolau et al. 2009). Since 2011, e-Learning courses have been developed to target the behaviours of stakeholders in relation to the accidental spread of IAS through work or leisure activities. The Better Biosecurity e-Learning course was developed in 2015 to raise awareness and encourage biosecurity practices among individuals who undertake work or research activities in the marine, freshwater and terrestrial environment. Nearly 5 years on, this study is the first to test the effectiveness of e-Learning on awareness and reported pro-environmental behaviour change in relation to biosecurity practices to reduce the risk of accidentally spreading IAS. Applying a common measurement of effectiveness, we measured field workers' awareness, risk perception, self-reported biosecurity practice and self-reported cleaning behaviour before, and 6 months after completing the Better Biosecurity e-Learning course for IAS. We conclude that the e-Learning course increased awareness and led to reported behaviour change; participants reported higher biosecurity scores after e-Learning.

In the literature, studies have found mixed results of the impacts of training on awareness. In a study looking at students' awareness of plagiarism and their perception of the seriousness of plagiarism before and after completing an online academic integrity training course, both students' awareness of plagiarism and their perceptions increased significantly after completing the training (Curtis et al. 2013). On the other hand, in a case study of two electricity companies, Perron et al. (2006) found that environmental training did not sufficiently increase employee environmental awareness of the company's environmental impacts. Consistent with Curtis et al. (2013), our study found as expected, that participants' awareness increased following training and professionals had higher awareness compared to students. Higher levels of awareness among professionals may be explained by infrastructure availability as well as an increase in interest and usefulness of the training topic compared to students (Grossman and Salas 2011; Grossman and BurkeSmalley 2018).

When we explored the data from all respondents, we also found that risk perceptions were higher among professionals before e-Learning compared to the students. Similarly, in a study looking at the risk perceptions of field researchers, Shannon et al. (2018a, b) found higher risk perceptions among those who undertook high risk activities in relation to IAS (sampling and aquatic fieldwork). Interestingly, whilst overall risk perception increased after training, professionals' risk perception did not change significantly following e-Learning unlike students' risk perceptions which increased. Previous studies have also found that simply being aware of risks does not always seem to be a strong factor for initiation of behaviours (Karanci et al. 2006). Wachinger et al. (2013) argue that whilst personal experience (of a natural hazard) has the most 
substantial impact on risk perception, if after training individuals do not have any negative experience, then they are more likely to believe that a future event will unlikely affect them, therefore their risk perception is unaltered and has the potential to decrease. We therefore argue that professionals' risk perception did not change significantly as a result from training due to the increase in awareness and continued experience and familiarity of IAS in the field.

Education is more than just the provision of information which does not always lead to behaviour change (Burke and Hutchins 2007; Hutchins and Burke 2007). Training aims to bridge this gap and provide participants with skills information to encourage individuals to act in an environmentally responsible manner (Shaw et al. 1999; Noesgaard and Ørngreen 2015). We found that self-reported biosecurity (measured as self-reported biosecurity practice and self-reported cleaning) improved after training, supporting our assumptions that training led both to increased awareness and to reported behavioural change. In our study we found that professionals reported higher levels of biosecurity practice before and after training compared to students. Behaviour change is most likely to occur when participants consider the training useful or necessary which in turn motivates their behaviour. Training is also dependent on the ability to use the skills whilst working, in comparison to education which focuses on knowledge and awareness raising (Grossman and Salas 2011). Sometimes individuals reported fail to apply, or transfer their learning to the work environment (Grossman and Burke-Smalley 2018). We therefore argue that professionals reported higher biosecurity practices compared to students as they could transfer the training to their job (Blume et al. 2010).

Training methods such as e-Learning have been introduced to try to reinforce and improve standards for good biosecurity in the field. Our study shows that the objectives of the e-Learning were met; awareness and risk perception increased as well as an improvement in reported biosecurity behaviour, with these changes evident 6 months post-training. However, Velada et al. (2007) argue that if people do not use their new skills for a while they are likely to forget them before being able to apply them. In the context of human resource management, Wexley and Latham (2002) found that whilst around 40 per cent of training content was transferred immediately, it fell to $25 \%$ after 6 months and a further $15 \%$ after 1 year. As with any training required by the organisation or institution to be repeated annually (e.g. fire training, IT security), biosecurity training should also be repeated by professionals in order to increase retention, sustain motivation and maintain a high level of awareness and behaviour in the future. Participants should take advantage of the freely available and flexible Better Biosecurity e-Learning course, and repeat the course annually, with participation encouraged by supervisors/heads of research departments. In addition to this, training should be coupled with support structures that encourage a desired behaviour and barriers should be addressed for engaging in this behaviour (e.g. cleaning facilities should be made available to encourage biosecurity practice) (Heimlich and Ardoin 2008). Methods to prevent the risk of introduction and spread are central to effective implementation of relevant legislation (e.g. CBD, MSFD and the EU IAS Regulation) and/or policy (e.g. the GB Invasive Non-Native Species Strategy for Great Britain). This study demonstrates that e-Learning is an effective tool to increase personal awareness of IAS and effect changes in behaviour to aid in reducing the risk of introduction/spread. Ideally e-Learning should be used as a tool, as part of a suite of methods, to aid in the implementation of national and international goals for the more effective management of IAS.

Acknowledgements The authors would like to thank all participants to the online survey for providing their time and to thank Veronica Volz for technical support. The research was funded by a Natural Environment Research Council Impact Accelerator award and a Natural Environment Research Council CASE studentship (NE/N008391/1) with the Centre for Environment Fisheries and Aquaculture Science. The research passed ethical review by the University of Leeds Ethics Committee (BIOSCI 15-023).

Authors' contribution CS, PDS, CHQ and AMD conceived the study and designed methodology and questionnaires; CS and DAW collected and analysed the data. CS led the writing of the manuscript. All authors contributed critically to the drafts and gave final approval for publication.

Data availability The data associated with this paper are openly available from the University of Leeds Data Repository. The data can be found here: www.doi.org/10.5285/ac271791b722-489c-9b68-b37316ec826c. 


\section{Compliance with ethical standards}

Conflict of interest The authors declare that they have no conflict of interest.

Open Access This article is licensed under a Creative Commons Attribution 4.0 International License, which permits use, sharing, adaptation, distribution and reproduction in any medium or format, as long as you give appropriate credit to the original author(s) and the source, provide a link to the Creative Commons licence, and indicate if changes were made. The images or other third party material in this article are included in the article's Creative Commons licence, unless indicated otherwise in a credit line to the material. If material is not included in the article's Creative Commons licence and your intended use is not permitted by statutory regulation or exceeds the permitted use, you will need to obtain permission directly from the copyright holder. To view a copy of this licence, visit http://creativecommons.org/licenses/by/4.0/.

\section{References}

Anderson LG, Dunn AM, Rosewarne PJ, Stebbing PD (2015) Invaders in hot water: a simple decontamination method to prevent the accidental spread of aquatic invasive non-native species. Biol Invasions 17:2287-2297. https://doi.org/ 10.1007/s10530-015-0875-6

Aquatic Nuisance Species Task Force (2020) Check Aquatic Hitchikers. http://stopaquatichitchhikers.org/. Accessed 20 Jan 2020

Arkorful N, Abaidoo V (2014) The role of e-Learning, advantages and disadvantages of its adoption in higher education. Int J Educ Res 2:398-410

Azeiteiro UM, Bacelar-Nicolau P, Caetano FJP, Caeiro S (2015) Education for sustainable development through e-Learning in higher education: experiences from Portugal. J Clean Prod 106:308-319. https://doi.org/10.1016/j.jclepro.2014. 11.056

Bacelar-Nicolau P, Caeiro S, Martinho AP et al (2009) e-Learning for the environment The Universidade Aberta (Portuguese Open Distance University) experience in the environmental sciences post-graduate courses. Int J Sustain High Educ 10:354-367. https://doi.org/10.1108/ 14676370910990701

Blume BD, Ford JK, Baldwin TT, Huang JL (2010) Transfer of training: a meta-analytic review. J Manage 36:1065-1105. https://doi.org/10.1177/0149206309352880

Bouhnik D, Marcus T (2006) Interaction in distance-learning courses. J Am Soc Inf Sci Technol 57:299-305. https://doi. org/10.1002/asi.20277

Boyes E, Stanisstreet M (2012) Environmental education for behaviour change: which actions should be targeted? Int J Sci Educ 34:1591-1614. https://doi.org/10.1080/ 09500693.2011.584079

Burke LA, Hutchins HM (2007) Training transfer: an integrative literature review. Hum Resour Dev Rev 6:263-296. https:// doi.org/10.1177/1534484307303035
Corral-Verdugo V (1997) Dual "realities" of conservation behavior: self-reports vs observations of re-use and recycling behaviour. J Environ Psychol 17:135-145. https:// doi.org/10.1006/jevp.1997.0048

Crawley M (2007) The R book. Wiley, Chichester

Creative Research (2018) Survey of Attitudes, Knowledge and Behaviour in Relation to Non-native Species. Shropshire, UK

Curtis GJ, Gouldthorp B, Thomas EF et al (2013) Online academic-integrity mastery training may improve students' awareness of, and attitudes toward, plagiarism. Psychol Learn Teach 12:282-289. https://doi.org/10.2304/plat. 2013.12.3.282

Defra (2020) Check, Clean, Dry. http://www.nonnativespecies. org/checkcleandry/. Accessed 20 Jan 2020

Estévez RA, Anderson CB, Pizarro JC, Burgman MA (2015) Clarifying values, risk perceptions, and attitudes to resolve or avoid social conflicts in invasive species management. Conserv Biol 29:19-30. https://doi.org/10.1111/cobi. 12359

Forestry Commission (2020) Keep it Clean. https://www.gov. uk/guidance/prevent-the-introduction-and-spread-of-treepests-and-diseases. Accessed 20 Jan 2020

GB Non-Native Species Secretariat (2020) e-Learning. http:// www.nonnativespecies.org/elearning/. Accessed 20 Jan 2020

Gilpin-Jackson Y, Bushe GR (2007) Leadership development training transfer: a case study of post-training determinants. J Manag Dev 26:980-1004. https://doi.org/10.1108/ 02621710710833423

Goodwin D, Raffin M, Jeffrey P, Smith HM (2018) Informing public attitudes to non-potable water reuse - The impact of message framing. Water Res 145:125-135. https://doi.org/ 10.1016/j.watres.2018.08.006

Grossman R, Burke-Smalley LA (2018) Context-dependent accountability strategies to improve the transfer of training: a proposed theoretical model and research propositions. Hum Resour Manag Rev 28:234-247. https://doi.org/10. 1016/j.hrmr.2017.08.001

Grossman R, Salas E (2011) The transfer of training: what really matters. Int J Train Dev 15:103-120. https://doi.org/10. 1111/j.1468-2419.2011.00373.x

Harrington SS, Walker BL (2009) The effects of computerbased fire safety training on the knowledge, attitudes, and practices of caregivers. J Contin Educ Nurs 40:79-86. https://doi.org/10.3928/00220124-20090201-07

Heimlich JE, Ardoin NM (2008) Understanding behavior to understand behavior change: a literature review. Environ Educ Res 14:215-237. https://doi.org/10.1080/ 13504620802148881

Hulme PE (2009) Trade, transport and trouble: managing invasive species pathways in an era of globalization. J Appl Ecol 46:10-18. https://doi.org/10.1111/j.1365-2664.2008. 01600.x

Hulme PE, Brundu G, Carboni M et al (2017) Integrating invasive species policies across ornamental horticulture supply chains to prevent plant invasions. J Appl Ecol 55:92-98. https://doi.org/10.1111/1365-2664.12953

Hungerford HR, Volk TL (1990) Changing learner behavior through environmental education. J Environ Educ 21:8-21. https://doi.org/10.1080/00958964.1990.10753743 
Hutchins HM, Burke LA (2007) Identifying trainers' knowledge of training transfer research findings - closing the gap between research and practice. Int J Train Dev 11:236-264. https://doi.org/10.1111/j.1468-2419.2007.00288.x

Jabbour CJC (2013) Environmental training in organisations: from a literature review to a framework for future research. Resour Conserv Recycl 74:144-155. https://doi.org/10. 1016/j.resconrec.2012.12.017

Karanci AN, Aksit B, Dirik G (2006) Impact of a community disaster awareness training program in Turkey: does it influence hazard-related cognitions and preparedness behaviors. Soc Behav Personal an Int J 33:243-258. https:// doi.org/10.2224/sbp.2005.33.3.243

Liaw S-S (2008) Investigating students' perceived satisfaction, behavioral intention, and effectiveness of e-Learning: a case study of the Blackboard system. Comput Educ 51:864-873. https://doi.org/10.1016/j.compedu.2007.09. 005

Liaw S-S, Huang H-M, Chen G-D (2007) Surveying instructor and learner attitudes toward e-Learning. Comput Educ 49:1066-1080. https://doi.org/10.1016/j.compedu.2006. 01.001

Lim H, Lee SG, Nam K (2007) Validating e-Learning factors affecting training effectiveness. Int J Inf Manag 27:22-35. https://doi.org/10.1016/j.ijinfomgt.2006.08.002

McKenzie-Mohr D, Schultz PW (2014) Choosing effective behavior change tools. Soc Mar Q 20:35-46. https://doi. org/10.1177/1524500413519257

Michie S, Van Stralen MM, West R (2011) The behaviour change wheel: a new method for characterising and designing behaviour change interventions. Implement Sci 6:42. https://doi.org/10.1186/1748-5908-6-42

Ministry for Primary Industries (2020) Check, Clean, Dry. https://www.mpi.govt.nz/travel-and-recreation/outdooractivities/check-clean-dry/. Accessed 20 Jan 2020

Noesgaard SS, Ørngreen R (2015) The effectiveness of e-Learning: an explorative and integrative review of the definitions, methodologies and factors that promote e-Learning effectiveness. Electron J e- Learn 13:278-290

O'Connor RE, Bord RJ, Fisher A (1999) Risk perceptions, general environmental beliefs, and willingness to address climate change. Risk Anal 19:461-471. https://doi.org/10. 1111/j.1539-6924.1999.tb00421.x

Owens S, Driffill L (2008) How to change attitudes and behaviours in the context of energy. Energy Policy 36:4412-4418. https://doi.org/10.1016/j.enpol.2008.09. 031

Perrings C, Dehnen-Schmutz K, Touza J, Williamson M (2005) How to manage biological invasions under globalization. Trends Ecol Evol 20:212-215. https://doi.org/10.1016/j. tree.2005.02.011

Perron GM, Côté RP, Duffy JF (2006) Improving environmental awareness training in business. J Clean Prod 14:551-562. https://doi.org/10.1016/j.jclepro.2005.07.006

R Core Team (2016) R: A Language and Environment for Statistical Computing. R Foundation for Statistical Computing, Vienna, Austria. https://www.r-project.org/. Accessed 23 Mar 2019
Rothlisberger JD, Chadderton WL, McNulty J, Lodge DM (2010) Aquatic invasive species transport via trailered boats: what is being moved, who is moving it, and what can be done. Fisheries 35:121-132. https://doi.org/10.1577/ 1548-8446-35.3.121

Salas E, Wilson KA, Priest HA, Guthrie JW (2006) Design, delivery, and evaluation of training systems. In: Salvendy G (ed) Handbook of human factors and ergonomics. Wiley, Florida, pp 472-512

Saul WC, Roy HE, Booy O et al (2017) Assessing patterns in introduction pathways of alien species by linking major invasion data bases. J Appl Ecol 54:657-669. https://doi. org/10.1111/1365-2664.12819

Sebire M, Rimmer G, Hicks R et al (2018) A preliminary investigation into biosecurity treatments to manage the invasive killer shrimp (Dikerogammarus villosus). Manag Biol Invasions 9:101-113. https://doi.org/10.3391/mbi. 2018.9.2.04

Shannon C, Quinn CH, Stebbing PD et al (2018a) The practical application of hot water to reduce the introduction and spread of aquatic invasive alien species. Manag Biol Invasions 9:417-423. https://doi.org/10.3391/mbi.2018.9. 4.05

Shannon C, Quinn CH, Sutlcliffe C et al (2018b) Exploring knowledge, perception of risk and biosecurity practices among researchers in the UK: a quantitative survey. Biol Invasions 20:399-411. https://doi.org/10.1007/s10530018-1837-6

Shaw L, Dingle P, Annandale D (1999) Implementation of environmental training programmes. Eco-Manag Audit 6:140-147. doi: 10.1002/(SICI)10990925(199909)6:3<140::AID-EMA108>3.0.CO;2-K

Sutcliffe C, Quinn CH, Shannon C et al (2018) Exploring the attitudes to and uptake of biosecurity practices for invasive non-native species: views amongst stakeholder organisations working in UK natural environments. Biol Invasions 20:399-411. https://doi.org/10.1007/s10530-017-1541-y

University of Leeds (2020) Better Biosecurity. https:// openeducation.blackboard.com/mooc-catalog/ courseDetails/view?course_id=_1189_1. Accessed 20 Jan 2020

Velada R, Caetano A, Michel JW et al (2007) The effects of training design, individual characteristics and work environment on transfer of training. Int $\mathrm{J}$ Train Dev 11:282-294. https://doi.org/10.1111/j.1468-2419.2007. 00286.x

Wachinger G, Renn O, Begg C, Kuhlicke C (2013) The risk perception paradox-implications for governance and communication of natural hazards. Risk Anal 33:1049-1065. https://doi.org/10.1111/j.1539-6924.2012. 01942.x

Wexley KN, Latham GP (2002) Developing and training human resources in organizations, $3 \mathrm{rd}$ edn. Pearson, Toronto

Publisher's Note Springer Nature remains neutral with regard to jurisdictional claims in published maps and institutional affiliations. 